\title{
I COLÓQUIO O ESPAÇO DO HABITAT DA OBRA DE HENRI LEFEBVRE: DO RURAL AO URBANO
}

\author{
Paula Dagnone Malavski*
}

De 16 a 18 de Novembro de 2010, foi realizado no departamento de Arquitetura e Urbanismo da Universidade Federal do Rio Grande do Norte (UFRN) o "I Colóquio O Espaço do Habitat da Obra de Henri Lefebvre: Do Rural ao Urbano, no campus de Natal".

O evento privilegiou diversas formas de diálogo sobre a importância da obra do filósofo francês para a compreensão da problemática do urbano no mundo contemporâneo destacando-se as mesas compostas por professores e alunos da casa e de outras instituições brasileiras como a Universidade Federal de Pernambuco (UFPE), Universidade de São Paulo (USP), Universidade Estadual Paulista "Júlio de Mesquita Filho" (UNESP), Universidade Federal do Rio de Janeiro (UFRJ), Universidade Federal do Ceará (UFCE), Universidade Federal de Goiás (UFG), Universidade Federal de Santa Catarina (UFSC), Universidade Federal Rural do Semiárido (UFERSA) e Universidade Potiguar (UNP). Dentre as universidades participantes destacaram-se os departamentos de Arquitetura e urbanismo, Geografia, Serviço Social, Ciências Sociais, Filosofia, entre outros.

1. Nesse evento apresentei o trabalho intitulado "A contribuição do pensamento de Henri Lefebvre para uma compreensão da problemática do urbano - o programa municipal
As atividades do evento foram compostas por mesas expositivas e sessões com as seguintes temáticas: Do Habitat ao Habitar, O Direito à cidade, Relação Campo-Cidade, Diálogos Interdisciplinares, Vida Cotidiana e Vida Social na Cidade ${ }^{1}$. A conferência inaugural do evento foi proferida pela Profa Dra Ana Fani Alessandri Carlos (Departamento de Geografia da Universidade de São Paulo), a qual expôs a importância e a contribuição do pensamento do autor para uma compreensão da produção do espaço urbano contemporâneo e seus diversos agentes envolvidos (Estado, Organizações não-governamentais, Movimentos Sociais e população).

Durante o evento ocorreu a defesa da Tese de Doutorado da professora do departamento de Arquitetura e Urbanismo (UFRN), Cíntia Soares de Oliveira intitulada "Henri Lefebvre - possibilidades teórico-metodológicas para a arquitetura e urbanismo, que fez uma abordagem, basicamente, sobre a obra " Do Rural ao Urbano" de Henri Lefebvre e sua possibilidade de ampliação do debate para o ensino de Arquitetura e Urbanismo.

Nota.

Alegra Centro (Santos - SP) e a Associação dos Cortiços do Centro (ACC), no eixo temático: Vida Social na Cidade. 